\title{
Combining photogrammetry and laser scanning for the recording and modelling of the Late Intermediate Period site of Pinchango Alto, Palpa, Peru
}

\author{
Karsten Lambers $^{\mathrm{a}, *}$, Henri Eisenbeiss ${ }^{\mathrm{b}}$, Martin Sauerbier ${ }^{\mathrm{b}}$, Denise Kupferschmidt ${ }^{\mathrm{a}}$, \\ Thomas Gaisecker $^{c}$, Soheil Sotoodeh ${ }^{b}$, Thomas Hanusch ${ }^{b}$ \\ ${ }^{a}$ German Archaeological Institute, Commission for Archaeology of Non European Cultures (KAAK), Endenicher Str. 41, D 53115 Bonn, Germany \\ ${ }^{\mathrm{b}}$ ETH Zurich, Institute of Geodesy and Photogrammetry, Wolfgang Pauli Str. 15, CH 8093 Zurich, Switzerland \\ ${ }^{\mathrm{c}}$ Riegl Laser Measurement Systems GmbH, Riedenburgstr. 48, A 3580 Horn, Austria
}

\begin{abstract}
This paper describes the 3D modelling of Pinchango Alto, Peru, based on a combination of image and range data. Digital photogrammetry and laser scanning allow archaeological sites to be recorded efficiently and in detail even under unfavourable conditions. In 2004 we documented Pinchango Alto, a typical site of the hitherto poorly studied Late Intermediate Period on the south coast of Peru, with the aim of conducting spatial archaeological analyses at different scales. The combined use of a mini helicopter and a terrestrial laser scanner, both equipped with a camera, allowed a fast yet accurate recording of the site and its stone architecture. In this paper we describe the research background, the 3D modelling based on different image and range data sets, and the resulting products that will serve as a basis for archaeological analysis.
\end{abstract}

Keywords: 3D modelling; Laser scanning; Photogrammetry; Andes; Nasca; Late Intermediate Period

\section{Introduction}

The region of Nasca and Palpa on the south coast of Peru is famous for the Nasca culture of the Early Intermediate Period (approximately $200 \mathrm{BC}$ AD 650; see Table 1) with its polychrome ceramics, fancy textiles, and large-scale geoglyphs in the desert in-between the fertile river oases (Silverman and Proulx, 2002). In contrast, the Late Intermediate Period (hereafter LIP; approximately AD 1000 1450) in this region is little known archaeologically. Before the start of a recent project (Conlee, 2000), few LIP sites had been studied, the most prominent being Huayurí or Ciudad Perdida in the Santa Cruz valley (Alfaro de Lanzone, 1974 75; Ojeda, 1981; Orefici, 1993). The size of Huayurí, its hidden location, and

\footnotetext{
* Corresponding author. Tel.: +49 1888771 220; fax: +49 1888771249. E mail address: lambers.kaak@gmx.de (K. Lambers).
}

the considerable amount of stone architecture and ceramics is typical of LIP sites in the Nasca region and presents a major challenge to archaeological documentation.

Since 1997, the Nasca-Palpa Archaeological Project directed by Markus Reindel and Johny Isla has been investigating the prehispanic cultural history of the Grande, Palpa, and Viscas valleys in the northern part of the Nasca drainage (Fig. 1) (Lambers, 2006; Reindel and Gruen, 2006). While large scale excavations focussed on sites of the Paracas and Nasca cultures (Isla and Reindel, 2006; Isla et al., 2003; Reindel and Isla, 2001), the aim of an extensive settlement survey was to document archaeological sites from all prehispanic periods in the three valleys (Isla and Reindel, 2005; Reindel et al., 1999). In the course of this work, about 140 LIP sites (out of a total of 735 sites) were recorded in a study area of $300 \mathrm{~km}^{2}$. The presence of large settlements and agricultural terraces suggests that the Palpa region reached a demographic peak during the Late Intermediate 
Table 1

Chronological table for the south coast of Peru (cp. Unkel, 2006)

\begin{tabular}{lll}
\hline Approximate dates & Period & Ceramic style \\
\hline $1450-1532$ A.D. & Late Horizon & Inca \\
$1000-1450$ A.D. & Late Intermediate Period & Ica Chincha \\
650 A.D. -1000 A.D. & Middle Horizon & Loro/Chakipampa \\
200 B.C. -650 A.D. & Early Intermediate Period & Nasca \\
800 B.C. -200 B.C. & Early Horizon & Ocucaje \\
1800 B.C. -800 B.C. & Formative Period & Pernil \\
\hline
\end{tabular}

Period, fostered by more humid conditions than in earlier and later periods (Eitel et al., 2005; Mächtle et al., 2006).

One of the most prominent LIP sites in the vicinity of Palpa is Pinchango in the foothills of Cerro Pinchango between the Grande and the Palpa rivers. Its upper part, Pinchango Alto, is located on a rocky spur and difficult to access (Fig. 2). As an exemplary LIP site in the Palpa region, it was decided to document Pinchango Alto using current geomatic technologies (Reindel and Isla, 2000). The aim was to create a high resolution textured 3D model of the site that would be used for architectural, functional, and contextual archaeological studies. During the 2004 field season, funding provided by the German Federal Ministry of Research and Education (BMBF), Bonn, and the generous cooperation of Riegl GmbH, Horn, Austria, allowed the site to be documented by two novel recording systems: an autonomous model helicopter as camera platform for the acquisition of aerial images (Eisenbeiss et al., 2005, 2006; Eisenbeiss and Zhang, 2006) and a Riegl LMS Z420i laser scanner with integrated camera providing terrestrial range and image data (Gaisecker, 2006). In this paper we focus on the combined processing and analysis of three data sets aerial images, terrestrial images, and terrestrial scan data and the $3 \mathrm{D}$ modelling of the site and its architecture.

In the following, the site is presented, and previous archaeological research in the region of Nasca and Palpa is briefly

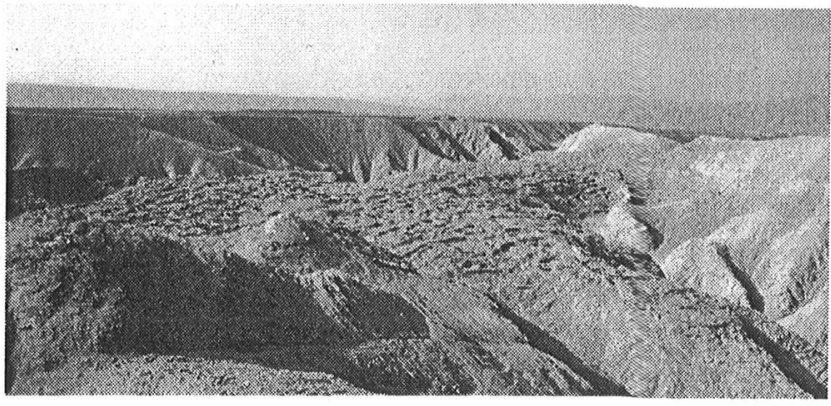

Fig. 2. The architectural remains of Pinchango Alto as seen from the north.

reviewed in order to define requirements for the documentation of LIP sites. The combined processing of range and image data and the generation of different 3D models of Pinchango Alto is then described next. The underlying aim of this paper is twofold: 1) to present the LIP site of Pinchango Alto in its archaeological context; and 2) to show how modern electro-optical recording technology can support the flexible and efficient documentation, modelling and analysis of archaeological sites.

\section{Pinchango Alto and the Late Intermediate Period in the region of Palpa and Nasca}

The Río Grande de Nasca drainage on the southern coast of modern Peru is formed by the Grande river and its eight affluents. Over the course of the millennia the rivers have cut deep ravines into the Andean foothills and the pediments to their west, thus forming narrow river valleys separated by ridges and plateaus. Today the region has a very arid climate with almost no annual precipitation. Agriculture is only possible on the valley bottom and is dependent upon the water which the rivers carry from the high Andes where they are fed by seasonal rainfalls.
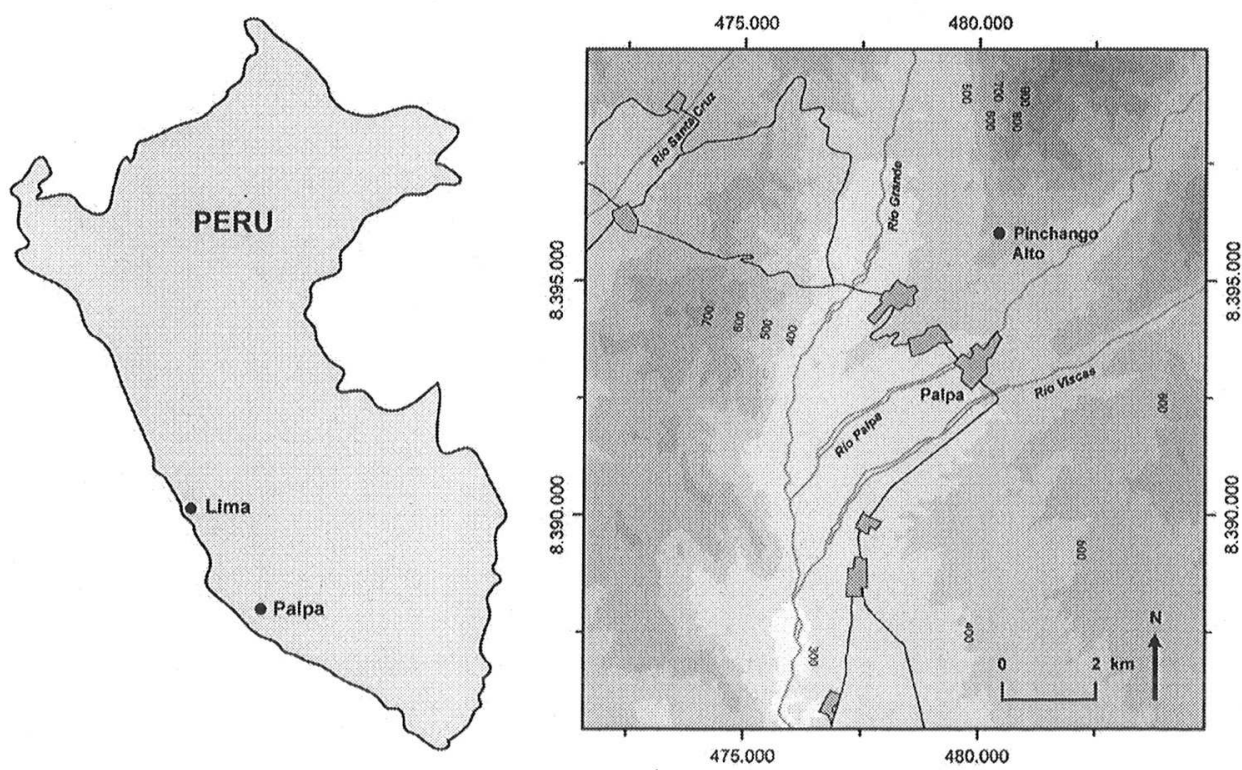

Fig. 1. The archaeological site of Pinchango Alto near Palpa on the south coast of Peru (coordinates: UTM 18S, WGS 84). 
Archaeological site surveys in the region (Browne, 1992; Browne and Baraybar, 1988; Isla and Reindel, 2005; Reindel et al., 1999) have shown that larger, permanent settlements first appeared during the Formative Period (Reindel and Isla, 2006) and increased in number during the Early Horizon and the time of the Nasca culture (Table 1). People lived mainly in small settlements with adobe buildings close to cultivable land. After a partial abandonment during the Middle Horizon (approximately AD 650 1000) the valleys saw a major resettlement during the Late Intermediate Period. The abundant ceramic sherds on the surface of many settlements show, through comparison to pottery from the Ica and Nasca valleys, that the LIP sites in the Grande and Palpa valleys formed part of a larger cultural region along the south coast (Conlee, 2000; Menzel, 1976; Vaughn et al., 2006). The population grew again to a level equal to or higher than during the Nasca period. At least in the northern part of the drainage LIP settlements were fewer yet larger than in earlier periods. Most sites were located well above earlier zones of habitation, along the slopes as well as on remote plateaus and spurs of the Andean foothills and at a considerable distance from any modern water source. This settlement pattern is remarkably different from previous periods, and its social and economic background has yet to be investigated in detail. As recent research indicates, LIP climate appears to have been more humid with reliable summer rains (Eitel et al., 2005; Mächtle et al., 2006). Apparently this allowed water to be caught and stored by means of terracing in side valleys that today are dry. The availability of local water sources would have increased the defensive potential of LIP sites. Whether or not this was a major concern to the ancient inhabitants of Pinchango Alto and other contemporaneous sites is as yet unclear, however.

Their remote location has saved many LIP settlements from severe looting leaving them in a relatively good state of preservation. Sites are composed of different architectural features, like narrow platforms with revetments of stones (along slopes and in steep gullies of hills), small agglutinated rooms, compounds with larger rooms, and open spaces. The clustering of these structures within certain parts of the sites points to internal divisions perhaps reflecting social stratification or economic specialisation. Most LIP sites have at least one, but normally several large grinding stones with smoothed surfaces, indicating prolonged use, that are distributed unevenly throughout the sites. Different ratios of structures at different sites in the region may indicate a certain specialisation of sites, given their contemporaneity.

Walls in LIP settlements were constructed using locally available, roughly rectangular boulders and rocks of variable sizes. Free-standing walls are normally double-faced with a thickness of 50 to $60 \mathrm{~cm}$ with an uneven surface. Originally walls appear to have been covered with some sort of plastering but only traces of it are left at any of the sites. Because walls tend to be partially or totally collapsed, mainly due to natural causes, it is often difficult to identify the original architecture.

So far, archaeological investigations of Late Intermediate Period sites in the region of Nasca and Palpa have been few and far between. The work that has been done concentrated on mapping and small scale excavations in Huayurí (Alfaro de Lanzone, 1974 75; Ojeda, 1981; Orefici, 1993), surveys in the northern Nasca drainage (Browne, 1992; Browne and Baraybar, 1988; Isla and Reindel, 2005; Reindel et al., 1999), and recent excavations in Pajonal Alto and La Tiza in the southern Nasca drainage (Conlee, 2000, 2003, 2005). Partly this lack of fieldwork might be due to the sheer size of some LIP sites. In the area studied by the Nasca-Palpa Archaeological Project alone there are ten sites with highly agglutinated architecture occupying an area of 5 ha or more each, rendering the process of accurate mapping for later analysis of settlement structures laborious and time consuming.

Pinchango is one of the best preserved sites from the Late Intermediate Period in the Palpa region und was therefore chosen for an exemplary study of a LIP site within the framework of the Nasca-Palpa Archaeological Project. Pinchango is situated about $3 \mathrm{~km}$ north of the modern town of Palpa $\left(14^{\circ} 30^{\prime} 27^{\prime \prime}\right.$ $\mathrm{S}, 75^{\circ} 11^{\prime} 03^{\prime \prime} \mathrm{W}$; Fig. 1). The site itself is composed of an upper and a lower part (Alto and Bajo respectively) together forming one of the largest LIP settlements in this region with a size of approximately 20 ha. Pinchango Alto occupies a nearly horizontal spur on Cresta de Sacramento between the Grande and Palpa valleys, about $150 \mathrm{~m}$ above the valley floor and 490 m.a.s.l. (Fig. 2), while Pinchango Bajo stretches along the northwestern slope towards the Grande valley. Access to Pinchango Alto seems to have been difficult at all times. To the east and south, the plateau is flanked by a deep gorge. To the north, access is only possible along a steep trail leading over a ridge, and this is where several defensive walls are located. There appears to have existed a direct access from the northwest via Pinchango Bajo. But, a modern irrigation channel cuts through the whole length of this side such that the alleged access path is no longer visible. The preserved wall height is about 40 to $70 \mathrm{~cm}$ but can reach a maximum of $1.5 \mathrm{~m}$. Grinding stones tend to cluster in the central part of the settlement where a series of holes were dug into the ground and underlying bedrock in ancient times. This has led to speculations about the settlement having functioned as a mining and mineral processing centre (Reindel, 2005), but the holes may also have served for the storage of other goods.

Considering the general characteristics of LIP sites in the region of Palpa and Nasca, and Pinchango Alto in particular, we defined three goals and levels for the intended investigation of the Late Intermediate Period in the Palpa region: 1) a spatial analysis of the site in its topographical context focussing on accessibility, visibility, and defensibility; 2) a functional study of the internal structure of the site; and 3) an exemplary documentation of LIP stone architecture and masonry. Such a multi-level investigation required 3D models of the site and its surroundings at various levels of resolution.

\section{3D modelling of the terrain surrounding Pinchango Alto}

For a spatial analysis of Pinchango Alto and its surroundings, a 3D model at a medium level of resolution was required that covers the site, the neighbouring hills and gorges, and the valleys 
to the north and south. Prior to the work at Pinchango Alto, a large scale photogrammetric survey of geoglyph sites from the Nasca period in the vicinity of Palpa had resulted in the generation of a 3D model covering an area of $89 \mathrm{~km}^{2}$ around the modern town of Palpa (Lambers, 2006; Sauerbier and Lambers, 2003). A digital surface model with an average point density of 1.6 points per $100 \mathrm{~m}^{2}$ and an orthophoto with a resolution of $25 \mathrm{~cm}$ were derived from analogue black and white aerial images with a scale of 1:7000 taken in 1998. The site of Pinchango Alto was included in this model due to the presence of a large geoglyph complex on a neighbouring plateau. This model gives an excellent idea of the setting of Pinchango Alto in the hills between the Palpa and the Grande valley. However, it does not show the stone walls of the site itself and the possible defensive walls surrounding it in sufficient detail as to allow reliable GISbased studies of visibility and accessibility. Thus, while the existing 3D model provided a good starting point for a regional spatial analysis, the site itself and its architecture needed to be modelled at higher resolution.

\section{3D modelling of the site of Pinchango Alto}

Within the site of Pinchango Alto, both the ground plan of the site and its stone architecture were to be documented. While the former required a vertical perspective, but not the highest possible resolution, for the latter we needed a nearhorizontal perspective and very high resolution. The difficult terrain at the site and time constraints during fieldwork required highly flexible and efficient surveying methods. These prerequisites led to the application of a terrestrial laser scanner, providing high resolution range and image data from a horizontal perspective, in combination with an autonomous mini helicopter, providing vertical aerial images. Prior to this, ground control points were measured with GPS to ensure the orientation and registration of the different data sets in a common coordinate system. The steps of the workflow as shown in Fig. 3 are explained in the following sections.

\subsection{Control point measurements}

In order to register the point clouds resulting from laser scanning as well as for orientation of the images taken by the laser and the helicopter cameras in a global coordinate system (UTM 18S, WGS 84), 80 signalised ground control points were distributed over the site of Pinchango Alto and measured using differential GPS. To this end, retro-reflecting cylinders provided by Riegl $\mathrm{GmbH}$ were combined with circular white cardboard discs (Fig. 4). While the reflectors were clearly marked in the laser scan point clouds, the cardboard discs were easily discernable in the aerial images. The reflectors were affixed to stones with a special glue easily removable without traces. The ground control points were measured with differential GPS in real time kinematic mode (RTKDGPS) in the UTM coordinate system with a 3D accuracy of $2 \mathrm{~cm}$ in horizontal and $3 \mathrm{~cm}$ in vertical direction after net-adjustment. Of the 80 measured ground control points (Fig. 5), some cylinders were afterwards not visible in the scan data or in the helicopter images, while others had shifted their position during the measurement due to weather conditions (dew, wind) and could thus not be used for analysis. Still, 39 points were used for the registration of the laser scan data using Riegl's RiSCANPRO software, while 48 points were used for registration by LS3D surface matching (described below). Finally, 41 points were used for the orientation of the helicopter images.

\subsection{Acquisition of range and image data using a Riegl LMS Z420i laser scanner}

The entire site of Pinchango Alto was recorded using the terrestrial laser scanner Riegl LMS Z420i (Gaisecker, 2006; Pinchango Alto project, 2006). This hybrid sensor combines the advantages of laser scanning and photogrammetry. The system is composed of a high performance long range laser scanner with a wide field of view and a calibrated digital camera firmly mounted to the scanning head of the laser scanner. The primary output delivers a point cloud representing a sampled replica of the object's surface. Due to the $360^{\circ}$ horizontal coverage per scan position, terrestrial laser scan data is well suited for an efficient 3D modelling of the vertical faces of standing walls and architecture (Böhler and Marbs, 2002; Kraus, 2004). In the case of partially destroyed walls an accurate documentation benefits from the high point density provided by laser scan technology. In many applications the

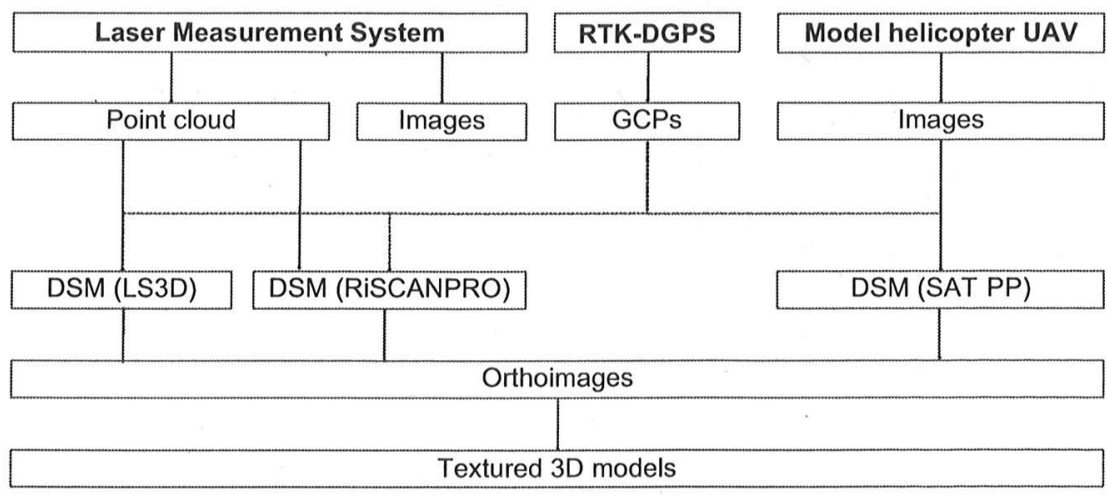

Fig. 3. Workflow of range and image data acquisition and processing. 


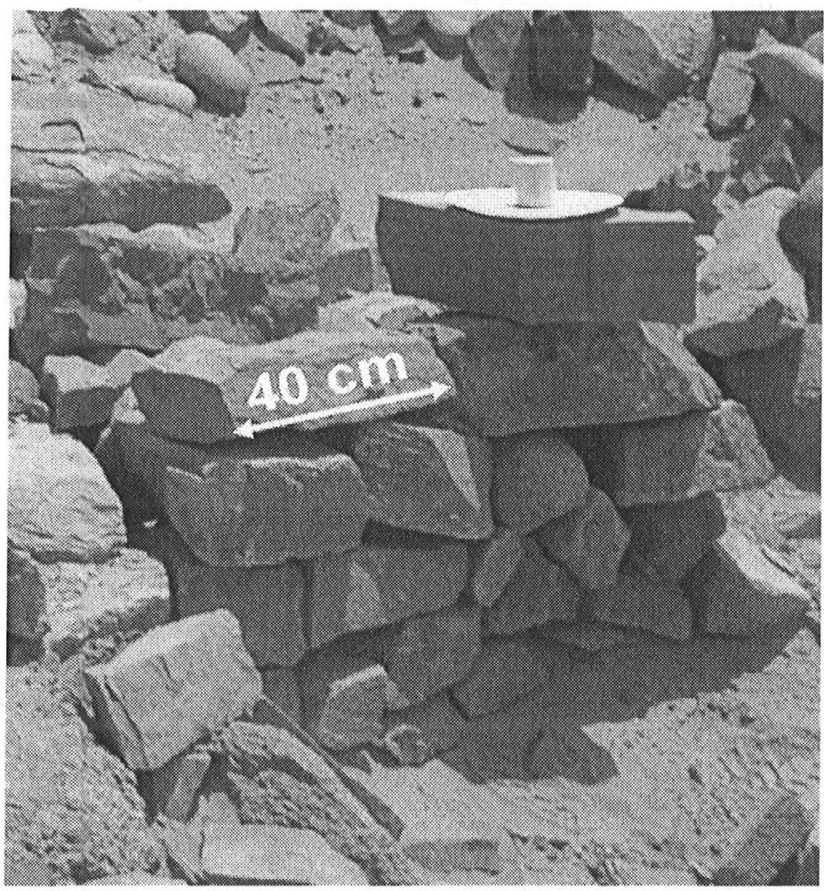

Fig. 4. Ground control point marker on a stone wall in Pinchango Alto.

user is not only interested in geometrical data, but also in visual information about the object's surface. This information is provided by automatically oriented high resolution images taken by the camera mounted on the scanner. The LMS Z420i scanner enabled laser distance measurements with a range of up to $1000 \mathrm{~m}$ (Riegl GmbH corporate, 2006). Table 2 summarises the key specifications of the LMS Z420i system.

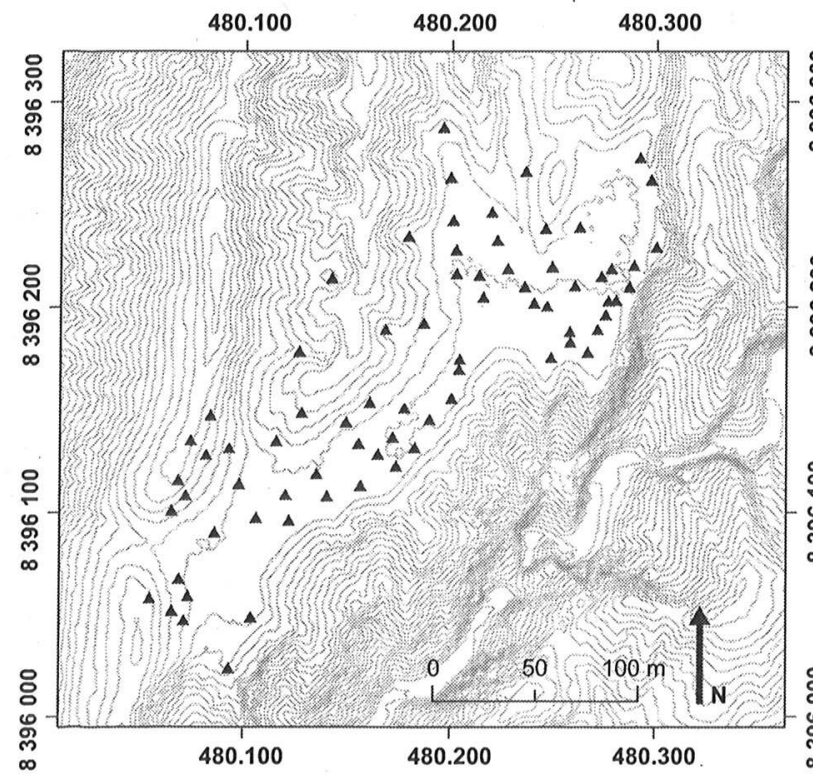

Table 2

Key specifications of the Riegl LMS Z420i laser scanner

\begin{tabular}{ll}
\hline Principle of distance measurement & Time of flight \\
Measurement range: & $1000 \mathrm{~m}$ (laser class 1$)$ \\
Accuracy: & $1 \mathrm{~cm}$ \\
Repeatability: & up to $4 \mathrm{~mm}$ \\
Measurement rate: & up to 12,000 points per second \\
Field of view: & $80^{\circ}$ vertically, $360^{\circ}$ horizontally \\
Data transfer: & TCP/IP interface, wireless \\
Control unit: & Standard PC/notebook \\
Camera: & Nikon D100, calibrated \\
Data processing software: & RiSCANPRO (Riegl), \\
& Polyworks (Innovmetric) \\
Beam divergence: & 0.25 mrad \\
\hline
\end{tabular}

The complete 3D documentation of Pinchango Alto took five days of fieldwork. First, an overview scan acquiring the whole area from an elevated position was conducted that later served as a reference to which the single scans were registered. The stone walls and terraces of the eastern part of Pinchango Alto, which are much better preserved than the western part, were then scanned from 47 scan positions (Fig. 5). The relatively high number of scan positions was necessary to minimise occlusions and to obtain both high resolution scan and image information of every single wall of the rather small rooms and enclosures. Nevertheless, the resulting raw point data still contained some occlusions due to the topography of the settlement. The less well preserved western part of the site was scanned from 13 positions, resulting in 61 scan positions for the whole site (Fig. 5). In the end, 57 of the 60 partial scans were registered to the overview scan, while three scans lacked overlap with it. The internal registration, calculated by using the 3D distances of tie points in order to generate rotation matrices and translation between the individual coordinate systems, yielded a standard deviation of $\pm 1 \mathrm{~cm}$

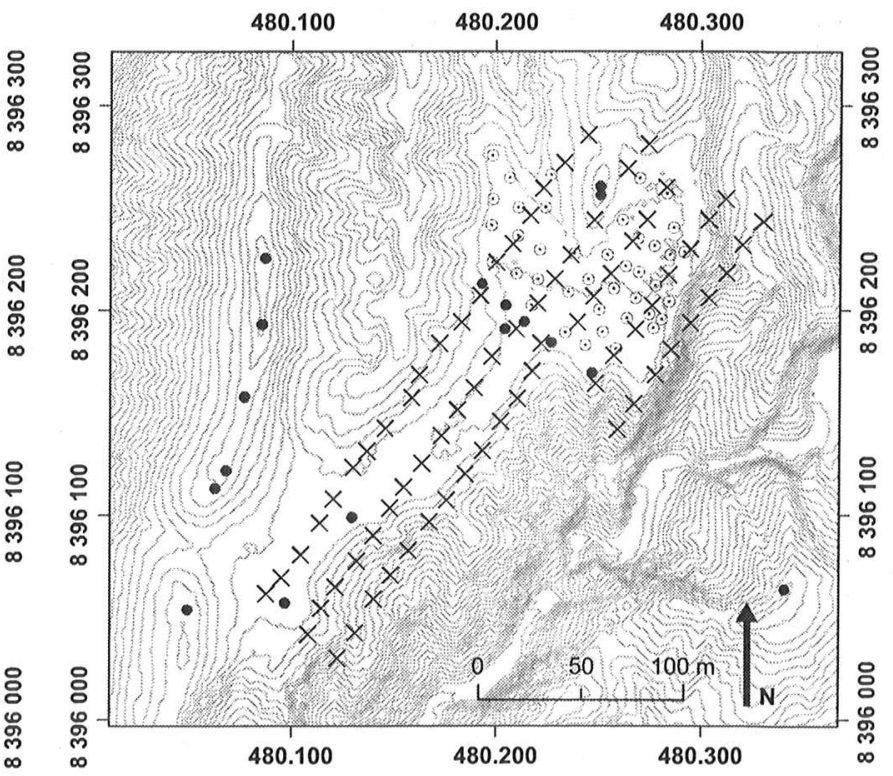

Fig. 5. Left: Distribution of ground control points over Pinchango Alto; Right: Distribution of projection centres of UAV images (crosses) and of scan positions for the eastern (circles) and western (dots) part of the site (coordinates: UTM 18S, WGS 84). 
for the scan data, whereas the standard deviation of the reflector positions was about $\pm 23 \mathrm{~cm}$, determined by the accuracy of the DGPS measurements. Data were registered parallel to acquisition such that a registered point cloud was available immediately after completion of the fieldwork. The final point cloud consisted of approximately 270 million single point measurements, out of which 144 million points resulted from the partial scans and 136 million points from the overview scan.

Additionally, 427 terrestrial images were taken with the CCD NIKON D100 camera with a resolution of 6.1 megapixels mounted on top of the laser scanner. These images provided nearly horizontal views of the stone walls and surrounding areas (Fig. 6). Depending on the distance of the data acquisition point from the object, different lenses were used with the camera. For close range objects we used a $14 \mathrm{~mm}$ lens and for distant objects a $50 \mathrm{~mm}$ lens from NIKON, respectively. Since the camera was firmly mounted on the scanner and had been calibrated prior to fieldwork, the images were absolutely oriented without the need for further registration.

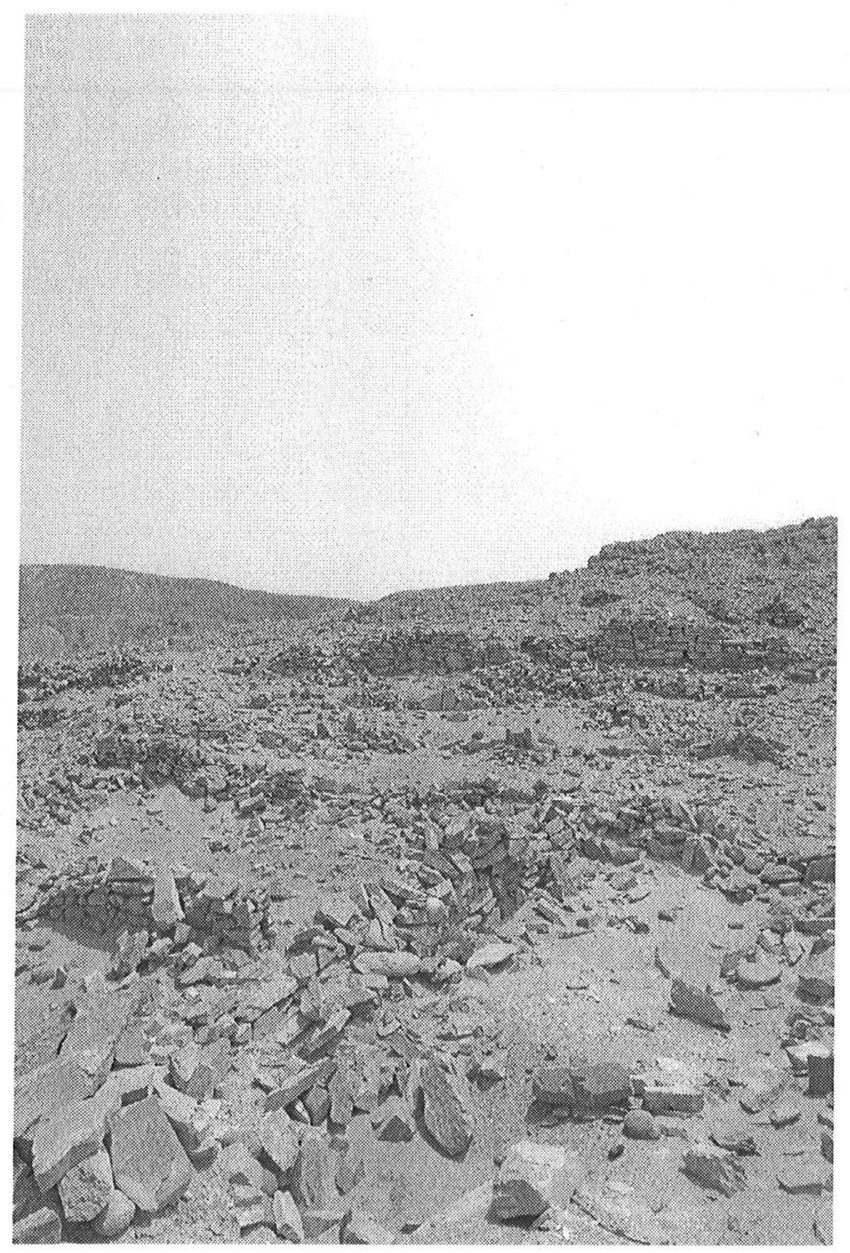

Fig. 6. Example of an image taken by the Nikon D100 camera mounted on the laser scanner.

\subsection{Processing of LMS Z420i data}

Innovmetric's 3D modelling software Polyworks was used for triangulation. Prior to this, the point cloud was reduced from a total number of 270 million points by means of the point decimation algorithm implemented in Riegl's RiSCANPRO software that uses an octree-based filter for averaging the measured points in volume elements of a defined size (Rodrigues et al., 2000). Outliers were removed from the reduced point cloud both semi-automatically and manually, again using RiSCANPRO. For the better preserved eastern part of Pinchango Alto the resolution was set to $10 \mathrm{~cm}$. This part of the model covers an area of approximately $100 \mathrm{~m} \times 100 \mathrm{~m}$ and consists of 1.5 million points and around 3 million triangles generated in Polyworks using a 2.5D Delauney triangulation. For the whole area of Pinchango Alto $(200 \mathrm{~m} \times 300 \mathrm{~m})$, a model with a mesh size of $20 \mathrm{~cm}$ consisting of 0.5 million points was generated. The result of the triangulation is a waterproofed digital surface model (hereafter RiSCANPRO laser DSM) that allows volume and section calculation.

In addition to the registration algorithm implemented in RiSCANPRO, a new surface based registration method developed at the Chair of Photogrammetry and Remote Sensing at ETH Zurich called Least Squares 3D Surface Matching (LS3D; see Gruen and Akca, 2005), was applied to the Pinchango Alto laser scan dataset in order to achieve a highly accurate globally registered point cloud. LS3D provides accurate surface matching results in reasonable processing time at the same level of accuracy as iterative closest-point based registration methods. It exploits the full potential of accuracy of the data owing to its powerful mathematical model and furthermore provides information about the registration accuracy from the resulting covariance matrix. After registration of the single scan positions, surface modelling was performed using Geomagic Studio (Geomagic) and ESRI's ArcGIS. Due to inefficient memory management of these software packages, surface modelling did not succeed in the original resolution. Therefore, a regular raster with a mesh size of $5 \mathrm{~cm}$ was interpolated from the measured points. The result is a second digital surface model (hereafter LS3D laser DSM) with a higher resolution than the RiSCANPRO laser DSM (Fig. 7).

\subsection{Acquisition of vertical aerial images using an autonomous mini helicopter}

In order to obtain a complementary dataset suited for the 3D modelling of the terrain surface on which the walls were built a series of vertical aerial images of Pinchango Alto were acquired with a Canon D60 CMOS camera (6.3 megapixels) carried by an autonomous model helicopter (or unmanned aerial/ airborne vehicle, UAV) (Abdullah et al., 2005; Eisenbeiss et al., 2005, 2006; Eisenbeiss and Zhang, 2006). The model helicopter featured an integrated GPS/INS navigation unit (global positioning system/inertial navigation system) as well as a stabiliser developed by ETH Zurich and weControl (weControl AG corporate, 2006). While the GPS/INS unit enabled semiautomatic navigation along a predefined flight path controlled 


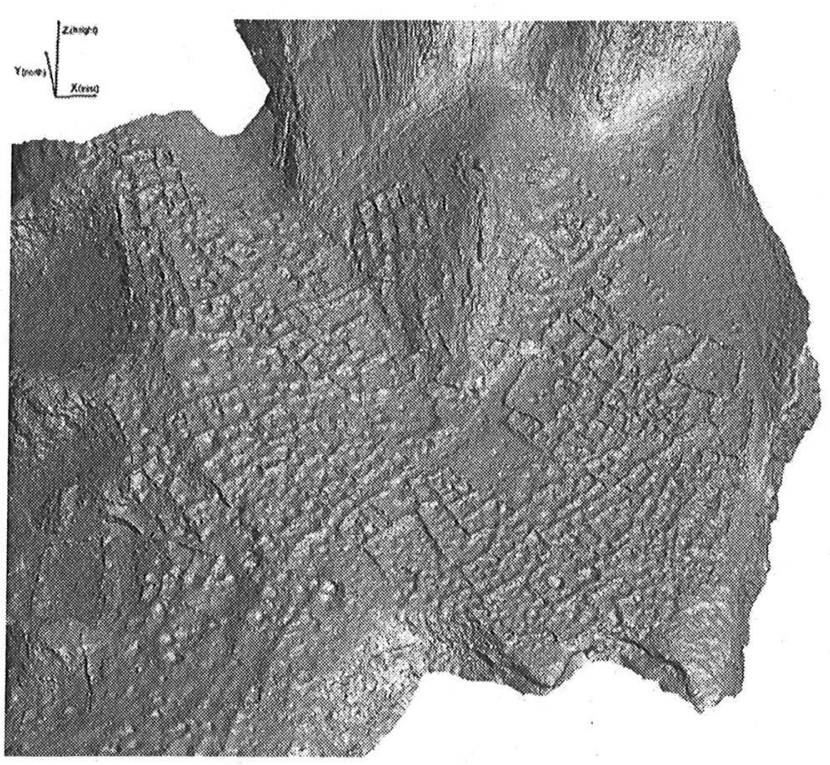

Fig. 7. Northeastern section of the LS3D laser DSM with $5 \mathrm{~cm}$ resolution.

via notebook by a ground-based operator, the stabiliser ensured a stable flight attitude and thus highly reliable image acquisition. The helicopter allowed a series of low altitude, digital aerial images to be taken with high precision at a scale and degree of overlap suitable for a photogrammetric recording of the terrain and the architecture (Eisenbeiss and Zhang, 2006; Eisenbeiss et al., 2005, 2006).

The flight planning for image acquisition was computed using inhouse software, taking into account the focal length of the camera $(14.26 \mathrm{~mm})$, pixel size $(7.37 \mu \mathrm{m} \times 7.37 \mu \mathrm{m})$, chip size $(22.7 \mathrm{~mm} \times 15.1 \mathrm{~mm})$, required image scale (1:4000), overlap between images in flight and across track direction (75\%), and corner points of the area of interest. The latter points were defined based on an orthoimage and DSM previously produced from analog aerial images acquired in 1998 at a scale of 1:7000 (Lambers, 2006). The flight path was then integrated into the flight control system of the helicopter. Eighty-five images were acquired that way, 70 of which were later used for photogrammetric processing (Fig. 5). One strip was not used since the remaining strips covered the site sufficiently.

The accurate flight planning and reliable image acquisition allowed for highly automated image processing. A high resolution digital surface model and an orthoimage were derived from the UAV images. An additional orthophoto was then produced by combining available data from both the UAV and the laser scanner (see below).

\subsection{Processing of image and range data and generation of surface models and orthophotos}

In order to generate a DSM from the UAV images we used the inhouse software SAT-PP (Satellite Imagery Precision Processing, see Zhang, 2005 and Zhang and Gruen, 2004), adapting it such that it was capable of handling aerial frame imagery and terrestrial images taken with a low cost digital camera. Due to the large overlap of $75 \%$ in and across flight direction, more than two images could be used simultaneously for matching, which increased the accuracy and reliability of the results (Zhang, 2005). The SAT-PP matching approach uses a coarse-to-fine hierarchical solution with a combination of multi-image, multi-primitive matching algorithms and automatic quality control. After edge enhancement in the original images and generation of image pyramids, image matching was performed by means of three kinds of features (feature points, grid points and edges), starting progressively from low-density features on the low resolution level of the image pyramid. A triangulated irregular network (TIN) of the DSM was reconstructed from the matched features on each level of the image pyramid by using the constrained Delauney triangulation method. Least squares matching was used to achieve more precise matches for all the matched features and for the identification of some false matches (Eisenbeiss et al., 2005, 2006; Zhang, 2005). Finally, from the matching results we derived an interpolated regular DSM with $10 \mathrm{~cm}$ resolution (hereafter UAV DSM).

Two orthoimages were produced from the UAV images using Leica's Photogrammetry Suite (LPS). It was not necessary to use every UAV image in flight direction and of each strip due to the high degree of overlap in and across flight direction. Thus, from the first, third and fifth strip, every other image was selected, resulting in a total of 26 images used for orthoimage production. One orthoimage was generated based on the UAV DSM, while the other was based on the RiSCANPRO laser DSM. The orthophoto with $3 \mathrm{~cm}$ footprint produced from the UAV images is shown in Fig. 8 as laid over the UAV DSM. In order to generate a second orthoimage, the RiSCANPRO laser DSM was used as elevation information for ortho-rectification of the oriented UAV images. Fig. 9 shows the UAV orthophoto as draped over the RiSCANPRO laser DSM.

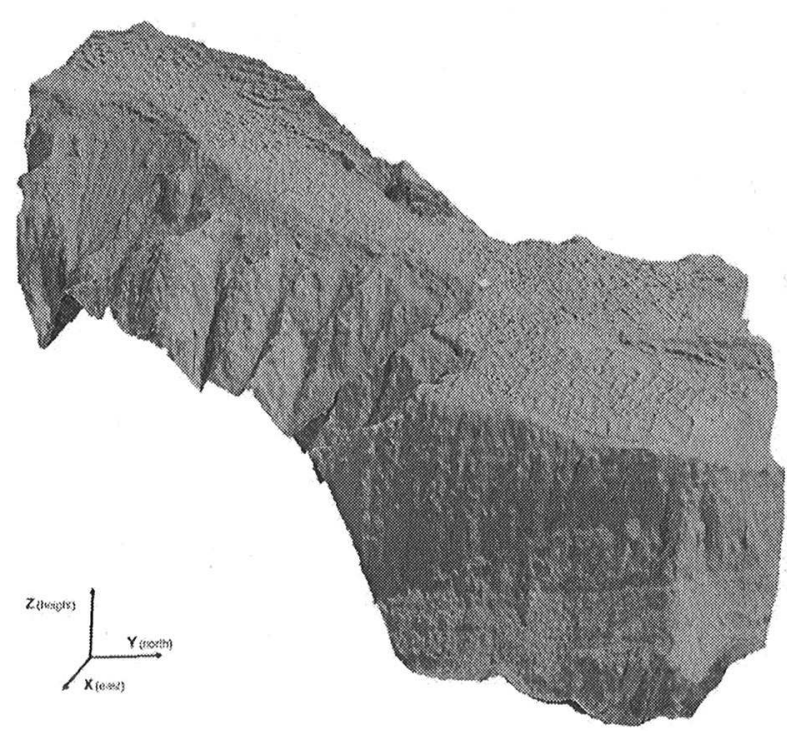

Fig. 8. The UAV orthophoto draped over the UAV DSM visualised using Autodesk's Maya. 


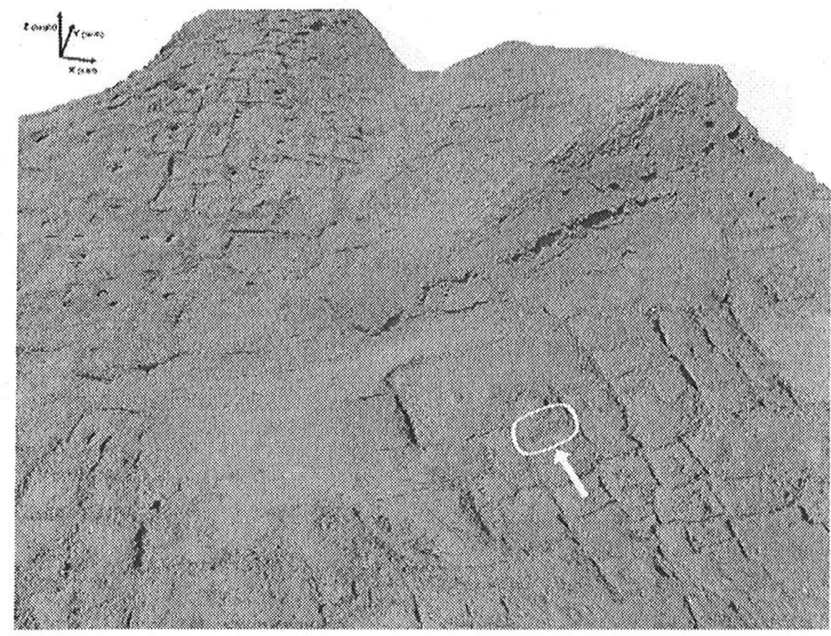

Fig. 9. Close up view of the UAV orthophoto draped over the RiSCANPRO laser DSM visualised using ESRI's ArcScene. The arrow indicates the wall shown in Fig. 11.

The different surface models and orthophotos described here provide a resolution that allows a detailed mapping of the location of walls, entrances, passage ways and other architectural features in order to reconstruct the ground plan of the site and conduct intra-site spatial and functional analyses. The models can also be inserted into the 3D model of the surroundings of Pinchango Alto described in Section 3, thus enabling reliable studies of the visibility and accessibility of the site in a GIS environment. Fig. 10 shows a combined 3D model for this purpose comprising the UAV DSM that covers the central part of Pinchango Alto, the RiSCANPRO laser DSM that covers the hills adjacent to the central part of Pinchango Alto, and the DSM derived from the aerial imagery used in the geoglyph study. All in all, we have generated different products

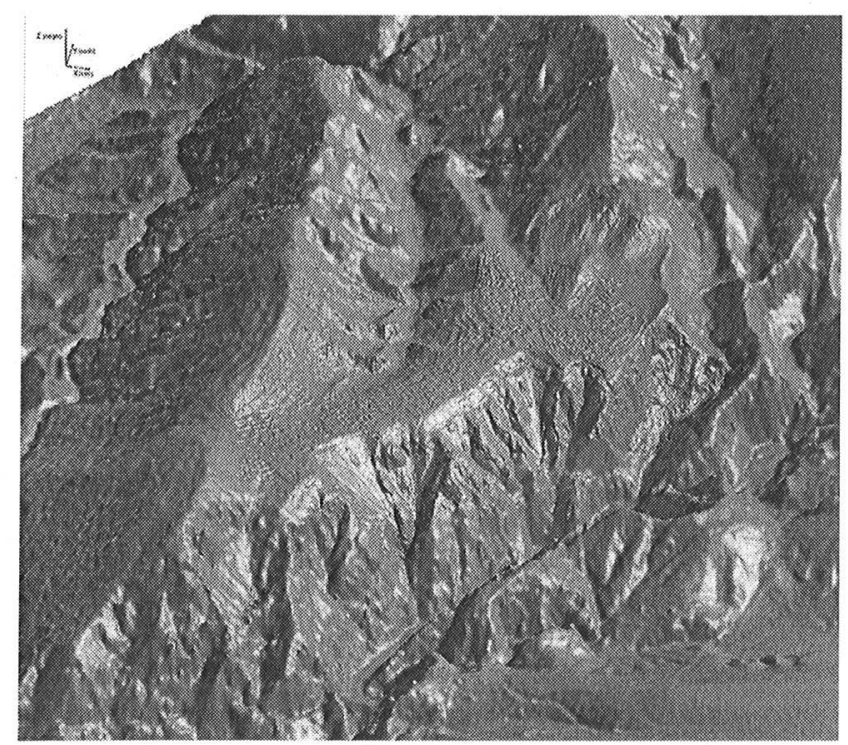

Fig. 10. Integrated DSM of Pinchango Alto and surroundings derived from UAV and laser data and aerial images (cp. Lambers, 2006). from different data sources using several processing methods and combinations of the obtained data (Table 3 ).

\section{3D modelling of stone architecture at Pinchango Alto}

While the above described 3D models enable spatial analysis on the regional and on the site level, the exemplary documentation of LIP stone architecture and masonry requires the highest possible resolution of both image and range data. This is provided by the data acquired with the Riegl LMS Z420i laser scanner with its integrated camera. Prior to the generation of a surface from the laser point cloud, outliers (erroneous measurements) had to be eliminated on a much higher level of detail than described in the previous section. For the visualisation of wall surfaces the best available image had then to be chosen to provide the information needed for a detailed 3D object extraction. For both steps we used inhouse software recently developed at ETH Zurich.

Surface reconstruction has to be conducted to generate a piecewise linear approximation of the object's surface, in this case the face of the wall, from the point cloud. Since the geometry of the object is inherently three-dimensional, 3D triangulation of the point cloud is required. Although the 2.5D Delaunay triangulation gives a partial solution, it yields an incorrect topological surface model. Thus, we accomplished surface modelling by a 3D Delaunay triangulation followed by surface extraction from the volumetric convex hull. However, cleaning the point cloud from outliers is necessary prior to surface reconstruction (Sotoodeh, 2006).

Several approaches exist for surface reconstruction. We have employed the most advanced sculpturing method and have contributed to the improvement of the solution using proximity graphs (explained in Marchette, 2004). This approach is quite helpful in distinguishing surface from nonsurface triangles especially in the case of under-sampled areas.

The application to the data set shows that the reconstructed surface has a correct topology as it is 2-manifold. Although there are some holes in the model due to under-sampling, the object is completely modelled in terms of coverage of the areas which fulfil a minimum sampling distance (Gonzalez and Wintz, 1977). The advantage of this approach is that walls measured at the back and front sides using different scan positions are reconstructed in one step, and no merging process is required afterwards. The reconstruction process is thus independent of the scan positions and is performed after the registration of the point clouds. Most of the process is accomplished with only minimal user interaction. In addition, no threshold or predefined value is required.

Image data acquired by the camera mounted on the laser scanner can then be used for automatic texture mapping, since the position and orientation of each camera location is determined relative to the reference coordinate system. As the camera is calibrated the images are undistorted according to the obtained calibration parameters.

For the selection of images usable for texture mapping we calculated the visible parts of the model for every image. For each vertex of the mesh we calculated the image coordinates 
Table 3

Overview of original data and derived products

\begin{tabular}{llll}
\hline Product & Type & Specifications & Amount \\
\cline { 4 - 4 } & & Resolution or Footprint & $\sim 270$ million points \\
\hline Original data & & $1-35 \mathrm{~cm}$ & $\sim 144$ million points \\
Laser scanner (raw data) & Point cloud & $1-35 \mathrm{~cm}$ & 427 \\
Laser scanner (processed data) & Point cloud & Depending on distance to object & 85 \\
Terrestrial images & Image & $\sim 3 \mathrm{~cm}$ & \\
UAV aerial images & Image & & $\sim 0.5$ million points \\
Digital elevation models & & $20 \mathrm{~cm}$ & $\sim 14.8$ million points \\
Laser DSM (RiSCANPRO) & Regular raster & $5 \mathrm{~cm}$ & $\sim 4.7$ million points \\
Laser DSM (LS3D) & Regular raster & $10 \mathrm{~cm}$ & $\sim 3.3$ million points \\
UAV DSM & Regular raster & $10 \mathrm{~cm}$ to $1 \mathrm{~m}$ & \\
Integrated DSM (laser, UAV, aerial images) & Irregular raster & & 1 \\
Orthophotos & & $3 \mathrm{~cm}$ & 1 \\
UAV DSM + UAV images & Orthoimage & $3 \mathrm{~cm}$ & \\
RiSCANPRO Laser DSM + UAV images & Orthoimage & & 1 \\
Textured 3D models & & $10 / 20 \mathrm{~cm}$ (Orthoimage/DSM) & 1 \\
Visualised using Maya & Video & $3 / 10 \mathrm{~cm}$ (Orthoimage/DSM) & \\
Visualised using ArcScene & Real time navigation &
\end{tabular}

using inhouse software. For visualisation of the textured model, the open source software Blender was used (Blender, 2006).

While modelling and texturing of single walls was generally successful using the above described approach, certain problems occurred with regard to a complete modelling of the site. Due to the complexity of the object structure, and despite the high available number of scanning and image
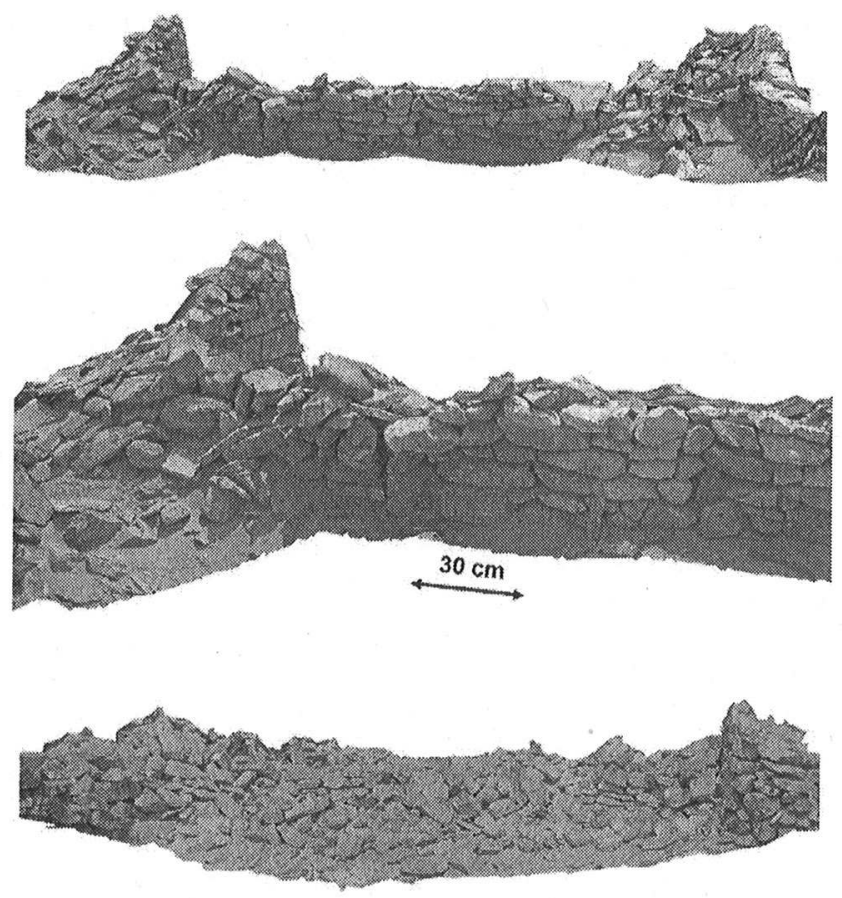

Fig. 11. Stone wall in the eastern part of Pinchango Alto (cp. Fig. 9) modelled and textured on the basis of LMS Z420i range and image data as described in Section 5. The upper image shows the well preserved south face, a close up of which is provided in the center, while the less well preserved north face is shown in the lower image. positions, a high number of occlusions still exists in both point clouds and images, which causes difficulties during surface reconstruction and texture mapping. Denser measurements in hitherto occluded areas would be required to fill these gaps. Furthermore, to conduct a complete texture mapping for the whole area some additional images would have to be taken. However, as the main goal of this working step is an exemplary study of LIP masonry, the high resolution modelling $(12 \mathrm{~cm})$ can be restricted to certain well preserved walls.

Taking these minor difficulties aside, the 3D model based on range and image data provided by the LMS Z420i laser scanner can now serve as a valuable data basis for archaeological analysis. The highly accurate 3D model (Fig. 11) enables a detailed documentation of LIP stone architecture at Pinchango Alto by measuring edges of stones and other architectural features, resulting in a $3 \mathrm{D}$ vector data set. This will enable the analysis of construction methods in settlements of the Late Intermediate Period in the region of Palpa. Having a better understanding of the construction techniques can also help in reconstructing wall heights, which in turn will aid the intended visibility analysis.

\section{Conclusions}

The application of two highly versatile recording systems, the Riegl LMS Z420i laser scanner and the UAV, allowed the Late Intermediate Period site of Pinchango Alto to be documented in high resolution and with high accuracy in basically one week of fieldwork. The combination of photogrammetry and laser scanning for 3D modelling has proven to be particularly efficient and flexible. Different levels of resolution and different viewing angles of the two recording systems used at Pinchango Alto allowed 3D models to be produced according to the specific requirements of archaeological analysis. These models of Pinchango Alto are a good starting point for a multi-level architectural, structural, and functional 
study of a typical large Late Intermediate Period site in the region of Palpa and Nasca.

\section{References}

Abdullah, Q.A., Collins, J., Edmundson, K., Grodecki, J., Heier, H., Hutton, J., Liddle, D., Mostafa, M., Mondello, C., Novak, K., Pacey, R., Scherzinger, B., 2005. Photogrammetric platforms. In: McGlone, J.C. (Ed.), Manual of Photogrammetry, 5th ed. American Society for Photo grammetry and Remote Sensing, Bethesda, pp. 677-730.

Alfaro de Lanzone, L., 1974-75. Una somera prospección en Huayurí (Que brada de Santa Cruz, Ica). Arqueología PUC 15-16, 83-103.

Blender, Open source 3D graphics creation website: http://www.blender.org/ $\mathrm{cms} /$ Home.2.0.html (accessed 25 November 2006)

Bohler, W., Marbs, A., 2002. 3D scanning instruments. In: W. Bohler (Ed.), Proceedings of the CIPA WG 6 International Workshop on Scanning for Cultural Heritage Recording, Ziti, Thessaloniki, pp. 9-18.

Browne, D.M., 1992. Further archaeological reconnaissance in the Province of Palpa, Department of Ica, Peru. In: Saunders, N.J. (Ed.), Ancient America: Contributions to New World Archaeology. Oxbow Monograph 24, Oxford, pp. 17-116.

Browne, D.M., Baraybar, J.P., 1988. An archaeological reconnaissance in the Province of Palpa, Department of Ica, Peru. In: Saunders, N.J., de Montmollin, O. (Eds.), Recent Studies in Pre Columbian Archaeology. BAR International Series 421, vol. ii, Oxford, pp. 299-325.

Conlee, C.A., 2000. Late Prehistoric Occupation of Pajonal Alto, Nasca, Peru: Implications for Imperial Collapse and Societal Reformation. University Microfilms, Ann Arbor.

Conlee, C.A., 2003. Local elites and the reformation of Late Intermediate Period sociopolitical and economic organization in Nasca, Peru. Latin American Antiquity 14, 47-65.

Conlee, C.A., 2005. The expansion, diversification, and segmentation of power in late prehispanic Nasca. In: Vaughn, K.J., Ogburn, D.E., Conlee, C.A. (Eds.), The Foundations of Power in the Prehispanic Andes, Archeological Papers of the American Anthropological Association 14. University of California Press for the American Anthropological Association, Washing ton D.C., pp. 211-223.

weControl AG corporate website, http://www.wecontrol.ch/ (accessed 10 July 2006).

Eisenbeiss, H., Zhang, L., 2006. Comparison of DSMs generated from mini UAV imagery and terrestrial laser scanner in a cultural heritage applica tion. International Archives of Photogrammetry, Remote Sensing and Spatial Information Sciences XXXVI 5, 90-96.

Eisenbeiss, H., Lambers, K., Sauerbier, M., Zhang, L., 2005. Photogrammet ric documentation of an archaeological site (Palpa, Peru) using an auton omous model helicopter. International Archives of Photogrammetry, Remote Sensing and Spatial Information Sciences XXXIV 5/C34 238-243.

Eisenbeiss, H., Lambers, K., Sauerbier, M., 2006. Photogrammetric recording of the archaeological site of Pinchango Alto (Peru) using a mini helicopter, In: A. Figueiredo, G.L. Velho (Eds.), The World is in Your Eyes - Pro ceedings of the 33rd CAA Conference, Tomar, Portugal, 21-24 March 2005, Trabalhos de Arqueologia, Instituto Português de Arqueologia, Lisbon.

Eitel, B., Hecht, S., Machtle, B., Schukraft, G., Kadereit, A., Wagner, G., Kromer, B., Unkel, I., Reindel, M., 2005. Geoarchaeological evidence from desert loess in the Nazca Palpa region, southern Peru: paleoenviron mental changes and their impact on pre Columbian cultures. Archaeome try $47,137-158$

Gaisecker, T., 2006. Pinchango Alto - 3D archaeology documentation using the hybrid 3D laser scan system of RIEGL. In: Baltsavias, E., Gruen, A., Van Gool, L., Pateraki, M. (Eds.), Recording, Modeling and Vi sualization of Cultural Heritage. Taylor \& Francis, London, pp. 459-464.

Gonzalez, R.C., Wintz, P., 1977. Digital Image Processing. Addison Wesley, Massachusetts.
Gruen, A., Akca, D., 2005. Least squares 3D surface and curve match ing. ISPRS Journal of Photogrammetry and Remote Sensing 59, 151174.

Isla, J., Reindel, M., 2005. New studies on the settlements and geoglyphs in Palpa, Peru. Andean Past 7, 57-92.

Isla, J., Reindel, M., 2006. Burial patterns and sociopolitical organization in Nasca 5 society. In: Isbell, W.H., Silverman, H. (Eds.), Andean Archaeol ogy III: North and South. Springer, New York, pp. 374-400.

Isla, J., Reindel, M., De La Torre, J.C., 2003. Jauranga: un sitio Paracas en el valle de Palpa, costa sur del Perú. Beitrage zur Allgemeinen und Verglei chenden Archaologie 23, 227-274.

Kraus, K., 2004. Photogrammetrie I: Photogrammetrische Informationen aus Photographien und Laserscanneraufnahmen, seventh ed., de Gruyter, Ber lin, New York.

Lambers, K., 2006. The geoglyphs of Palpa, Peru: documentation, analysis, and interpretation, Forschungen zur Archaologie Aussereuropaischer Kul turen 2, Linden Soft, Aichwald.

Machtle, B., Eitel, B., Kadereit, A., Unkel, I., 2006. Holocene environmental changes in the northern Atacama desert, southern Peru ( $\left.14^{\circ} 30^{\prime} \mathrm{S}\right)$ and their impact on the rise and fall of pre Columbian cultures. Zeitschrift fur Geo morphologie, supplement vol. 142, 47-62.

Marchette, D.J., 2004. Random Graphs for Statistical Pattern Recognition. Wiley, Hoboken.

Menzel, D., 1976. Pottery Style and Society in Ancient Peru: Art as a Mirror of History in the Ica Valley, 1350-1570. University of California Press, Berkeley.

Ojeda, B., 1981. Ciudad perdida de Huayurí, Boletín de Lima 16-18, 78-82.

Orefici, G., 1993. Nasca: arte e società del popolo de geoglifi. Corpus Preco lombiano. Jaca Book, Milano.

Pinchango Alto project, website, http://www.photogrammetry.ethz.ch/re search/pinchango/ (accessed 10 July 2006).

Reindel, M., 2005. Pinchango Alto: a gold miners' settlement in Palpa, south ern Peru. In: Eeckhout, P., Le Fort, G. (Eds.), Wars and Conflicts in Pre hispanic Mesoamerica and the Andes. BAR International Series 1385. Archaeopress, Oxford, pp. 90-98.

Reindel, M., Gruen, A., 2006. The Nasca Palpa Project: a cooperative approach of archaeology, archaeometry and photogrammetry. In: Baltsavias, E., Gruen, A., Van Gool, L., Pateraki, M. (Eds.), Recording, Modeling and Visualization of Cultural Heritage. Taylor \& Francis, Lon don, pp. 21-32.

Reindel, M., Isla, J., 2000. Ausgrabungen in Los Molinos und La Muña. Ergebnisse der Grabungskampagne 1999 des Archaologischen Projektes Nasca Palpa, Sud Peru, SLSA Jahresbericht 1999, 67-95.

Reindel, M., Isla, J., 2001. Los Molinos und La Muña. Zwei Siedlungszentren der Nasca Kultur in Palpa, Sud Peru/Los Molinos y La Muña. Dos centros administrativos de la cultura Nasca en Palpa, costa sur del Perú, Beitrage zur Allgemeinen und Vergleichenden Archaologie 21, 241-319.

Reindel, M., Isla, J., 2006. Archaologisches Projekt 'Paracas in Palpa', Peru: Ausgrabungen und Forschungen im Jahr 2005. SLSA Jahresbericht 2005 , 30-59.

Reindel, M., Isla, J., Koschmieder, K., 1999. Vorspanische Siedlungen und Bodenzeichnungen in Palpa, Sud Peru/Asentamientos prehispánicos y geoglifos en Palpa, costa sur del Perú. Beitrage zur Allgemeinen und Ver gleichenden Archaologie 19, 313-381.

Riegl GmbH corporate website, http://www.riegl.com/ (accessed 10 July 2006).

Rodrigues, J., Loke, R.E., du Buf, J.M.H., 2000. Fast segmentation of 3D data using an octree. In: Proceedings of the 11th Portuguese Conference on Pat tern Recognition RECPAD, Porto, May 11-12, 2000, Associaçao Portu guesa de Reconhecimento de Padroes, Porto, pp. 185-189.

Sauerbier, M., Lambers, K., 2003. A 3D model of the Nasca lines at Palpa (Peru), International Archives of Photogrammetry, Remote Sensing and Spatial Information Sciences, vol. XXXIV 5/W10, on CD ROM.

Silverman, H., Proulx, D., 2002. The Nasca, The Peoples of America. Black well, Malden, Oxford.

Sotoodeh, S., 2006. Outlier detection in laser scanner point clouds. Interna tional Archives of Photogrammetry, Remote Sensing and Spatial Informa tion Sciences XXXVI 5, 297-302. 
Unkel, I., 2006. AMS 14C Analysen zur Rekonstruktion der Landschafts und Kulturgeschichte in der Region Palpa (S Peru), University of Hei delberg, http://www.ub.uni heidelberg.de/archiv/6311 (accessed 10 July 2006).

Vaughn, K.J., Conlee, C.A., Neff, H., Schreiber, K., 2006. Ceramic production in ancient Nasca: provenance analysis of pottery from the Early Nasca and Tiza cultures through INAA. Journal of Archaeological Science 33, 681-689.
Zhang, L., 2005. Automatic Digital Surface Model (DSM) Generation from Linear Array Images, IGP Mitteilungen 88, Institute of Geodesy and Photogrammetry, Zurich.

Zhang, L., Gruen, A., 2004. Automatic DSM generation from linear array imagery data. International Archives of Photogrammetry, Remote Sensing and Spatial Information Sciences XXXVB3, $128-133$. 